\title{
OS USOS DOS TERMOS MANDIOCA E MACAXEIRA \\ NO ESTADO DO ACRE
}

\section{THE TERMINOLOGY USE OF MANIOC AND CASSAVA IN ACRE STATE}

\author{
Simone Cordeiro Oliveira Pinheiro ${ }^{1}$
}

\begin{abstract}
RESUMO: Mandioca e macaxeira são duas formas utilizadas popularmente para designar a espécie Manihot esculenta Crantz no estado do Acre. Contudo, observamos que no processo de designação dos derivados da planta, a escolha de uma unidade léxica pela outra não ocorre de forma aleatória, mas obedece padrões específicos. $O$ presente artigo tem como objetivo apresentar e analisar os usos das unidades terminológicas mandioca e macaxeira presentes no corpus de estudo intitulado TERMani - Terminologia da Mandioca. O referido corpus foi utilizado para a constituição do Dicionário Terminológico Onomasiológico dos Termos Fundamentais da Mandioca (Cordeiro-Oliveira, 2019). Para a realização de nossa pesquisa buscamos subsídios teóricos em Wüster ([Felber, 1979], 1998), Cabré ([1993], 2005), Maciel (2001), Barros (2004), Krieger e Finatto (2004), Berber Sardinha (2004), Othero e Menuzzi (2005) e Orenha-Ottaiano (2008). Os dados foram analisados no programa WordSmith Tools (SCOTT, 2012) versão 6.0 e revelaram uma regularidade quanto a escolha das unidades léxicas.
\end{abstract}

PALAVRAS-CHAVE: estudo terminológico; mandioca; macaxeira; análise linguística

\begin{abstract}
Manioc and cassava are two terms ordinarily used to name in Acre State the specie Manihot esculenta Crantz. Nevertheless, we identified that in the nomination process of the plant derivatives the selecting of lexical unity do not occur randomly, and then follows certain standards. This study aims to present and analyze the use of terminology units of manioc and cassava existing in the study corpus TERMani - Terminology of Manioc. This corpus was used to compose the Terminological and Onomasiological Dictionary of Main Terms of Manioc (Cordeiro-Oliveira, 2019). In order to accomplish this study the theoretical framework is based on Wüster ([Felber, 1979], 1998), Cabré ([1993], 2005), Maciel (2001), Barros (2004), Krieger e Finatto (2004), Berber Sardinha (2004), Othero e Menuzzi (2005) e Orenha-Ottaiano (2008). The data were analyzed with WordSmith Tools software version 6.0 (SCOTT, 2015) displayed regularity related to the chosen of lexical unities.
\end{abstract}

KEYWORDS: terminology study; manioc; cassava; linguistic analysis

\section{Introdução}

\footnotetext{
${ }^{1}$ Doutora em Estudos Linguísticos pela UNESP/Ibilce - Câmpus de São José do Rio Preto. Professora da UFAC, Câmpus de Cruzeiro do Sul (Floresta) - Centro de Educação e Letras (CEL). Projeto com apoio Universidade Federal do Acre.
} 
Manihot esculenta Crantz é uma importante espécie da cultura alimentar brasileira popularmente conhecida como mandioca, macaxeira, aipim, pão-de-pobre etc. Cultivada em mais de 100 países de acordo com dados da Empresa Brasileira de Pesquisa Agropecuária (Embrapa); o Brasil participa com 10\% da produção mundial, sendo o segundo maior produtor do mundo. No contexto acreano, constitui o principal produto agrícola, representando $18 \%$ em volume e $48 \%$ em valor bruto de produção.

Mais de 20 mil pequenos agricultores cultivam a planta no estado do Acre. Na região do Alto Juruá ${ }^{2}$ a raiz tem grande valor agrícola especialmente para o município de Cruzeiro do Sul por ser a matéria-prima da "Farinha de Mandioca de Cruzeiro do Sul", produto de expressivo valor cultural para os habitantes local. Além da farinha, outros derivados da mandioca são produzidos na região; dentre eles destacamos a tapioca, beiju, bolo de macaxeira, beléu, broa, biscoito de goma, caiçuma, quibe de macaxeira e o tucupi.

No estado do Acre, a planta é popularmente conhecida como mandioca e macaxeira. Aparentemente, não há distinção entre a escolha de uma unidade léxica pela outra. Contudo, quando fazemos uma análise mais minuciosa do uso dos termos, percebemos que o uso de uma forma pela outra, no processo de designação dos produtos derivados da planta, se dá de maneira, aparentemente, consciente.

Assim, desenvolvemos essa pesquisa com o intuito de investigarmos os usos das unidades léxicas mandioca e macaxeira no estado do Acre. Inicialmente, fazemos uma breve explanação da cultura da mandioca no estado com o propósito de destacar a importância do tubérculo para essa região Amazônica, não só no aspecto socioeconômico; mas, sobretudo, cultural. Em seguida, apresentamos o referencial teórico que utilizamos para o nosso estudo. Trata-se de uma pesquisa terminológica, cuja metodologia se baseia na Linguística de Corpus. Em ato contínuo, mostramos a metodologia da pesquisa; momento em que descrevemos as etapas seguidas para a realização deste estudo. Posteriormente, procedemos a análise dos dados e os resultados obtidos.

Na próxima seção apresentamos alguns aspectos da cultura da mandioca no estado do Acre, sua representatividade socioeconômica e cultural para os sujeitos que vivem no estado mais ao ocidente do território brasileiro.

\footnotetext{
${ }^{2}$ A região do Alto Juruá, popularmente conhecida como Vale do Juruá, é uma microrregião situada no extremo noroeste do estado do Acre. Ela é composta por cinco municípios: Cruzeiro do Sul, Mâncio Lima, Marechal Thaumaturgo, Porto Walter e Rodrigues Alves. Dentre estes, o município de Cruzeiro do Sul destaca-se quanto à extensão territorial, número de habitantes e PIB; sendo por isso, considerado a capital do Vale do Juruá.
} 


\section{A cultura da mandioca no estado do Acre}

A mandioca é o principal produto agrícola do estado do Acre, representando $18 \%$ em volume e $48 \%$ em valor bruto de produção total (Bergo, 1993). Segundo dados do Instituto Brasileiro de Geografia e Estatística (IBGE, 2009), em todo o estado mais de 20 mil pequenos agricultores trabalham no plantio da mandioca; desse quantitativo, grande parte é destinada para a produção de farinha. Em 2010, os municípios que compõem o Vale do Juruá foram responsáveis pela produção de 307.202 toneladas do tubérculo, segundo dados do IBGE destacados por Velthem e Katz (2012).

Dentre os municípios acreanos, Cruzeiro do Sul se destaca pela boa qualidade da farinha que produz: branca, amarela, com coco, fina, grossa são alguns tipos de farinha que podem ser encontradas nos grandes e pequenos comércios da região. A importância do produto para os municípios do Vale do Juruá, em especial para a cidade de Cruzeiro do Sul, é, sobretudo, cultural. O derivado recebe o nome da cidade "Farinha de Mandioca de Cruzeiro do Sul" ou "Farinha de Cruzeiro do Sul", como forma de caracterizar o local de onde é produzido e indicar a qualidade do produto. No ano de 2017 a farinha de Cruzeiro do Sul recebeu o Selo de Indicação Geográfica (IG) e passou a ser o primeiro produto do estado do Acre e a primeira farinha de mandioca do Brasil a receber o selo.

A expressividade da farinha para a economia e cultura da região do Vale do Juruá resultou na criação da Cooperativa Nova Aliança dos Produtores de Farinha do Vale do Juruá (Cooperfarinha), no Mercado da Farinha e no Festival da Farinha. O derivado acompanha, praticamente, todos os pratos regionais. Apesar de ser o principal produto, outros derivados da planta também se destacam pelas peculiaridades na produção, qualidade e sabor. Da "massa fina" é produzido o mingau, muito utilizado na alimentação de crianças; a "goma" é utilizada na elaboração de "tapiocas" e "beijus"; a "farinha de tapioca" é extraída do processo de peneiragem da goma, e é utilizada na composição de bolos ou na mistura de vinhos regionais como o açaí, buriti e o patauá; o "tucupi” é utilizado no preparo de molhos.

Cumpre destacar que esses derivados, massa fina, goma, farinha de tapioca, tucupi, assim como outros, são resultados do reaproveitamento do estado da mandioca em uma ou mais etapas do processo de produção da farinha. Ressaltamos, ainda, o "quibe de macaxeira", "bolo de macaxeira", "beléu”, "broa", "caiçuma” e o "biscoito de goma". Ao contrário do que ocorre no processo de produção da farinha, que é de natureza familiar - com homens, mulheres e 
crianças; os biscoitos de goma são produzidos apenas por mulheres, trabalhadoras rurais que incrementam a renda familiar com a atividade.

Tendo em vista a importância da cultura da mandioca para o estado do Acre e de maneira geral para a agricultura brasileira, decidimos estudar este conjunto terminológico. Como resultado de nossa pesquisa, realizamos a compilação do "Dicionário Terminológico Onomasiológico dos Termos Fundamentais da Mandioca”. A obra é monolíngue, escrita em língua portuguesa, variante brasileira; possui 446 termos, destes 284 são termos privilegiados e 162 correspondem a termos remissivos (variantes). O dicionário foi constituído a partir de um corpus especializado, doravante CE, denominado TERMani - Terminologia da Mandioca.

Para esta pesquisa, temos interesse na análise das unidades lexicais mandioca e macaxeira presentes no TERMani; uma vez que identificamos que, no estado do Acre, as escolhas das duas lexias, no processo de denominação dos derivados da planta, não ocorrem de forma aleatória. Na próxima seção apresentamos as duas teorias da Terminologia e as contribuições da Linguística de Corpus para as pesquisas terminológicas.

\section{Fundamentação teórica}

\section{As duas teorias da Terminologia e as contribuições da Linguística de Corpus}

O uso das terminologias na atualidade possibilita expressiva funcionalidade para a linguagem humana por permitir a comunicação nos diversos campos de atuação. A partir do ano de 1972 a Terminologia recebeu a feição de disciplina científica e o tratamento dado ao seu objeto de estudo, o termo, evoluiu na medida em que ocorreu o amadurecimento das reflexões quanto ao seu uso enquanto elemento de comunicação. A Teoria Geral da Terminologia, doravante TGT, e a Teoria Comunicativa da Terminologia, doravante TCT, contribuíram bastante para a consolidação do estudo dos termos a partir das perspectivas linguística e gramatical.

Na TGT, proposta pelo engenheiro austríaco Eugen Wüster (1898 - 1977), o termo é concebido enquanto recurso de identificação dos objetos e coisas. Sua funcionalidade reside na capacidade de tornar a comunicação especializada eficiente, monossêmica; ou seja, sem "problemas de ambiguidade"3. O interesse pela normalização da linguagem profissional

\footnotetext{
${ }^{3} \mathrm{O}$ interesse de Wüster pelo léxico temático não tinha qualquer relação linguística, haja vista que ele não era linguista, mas um industrial e professor "envolvido pelo espírito de desenvolvimento da tecnologia e da normalização tecnológica que vigorava na Alemanha dos anos de 1920” (BARROS, 2004, p. 53).
} 
possibilitou o desenvolvimento de algumas reflexões a respeito do aspecto prático da Terminologia. A importância da teoria de Wüster reside na organização sistemática dos princípios em torno dos processos de normatização e classificação dos termos.

Em contrapartida, a TCT, proposta por Maria Teresa Cabré e por um grupo de pesquisadores do Instituto de Linguística Aplicada, da Universidade Pompeu Fabra, em Barcelona, surge como uma alternativa para se pensar o objeto de estudo da Terminologia a partir de uma perspectiva comunicativa. Na TCT, o termo recebe o tratamento linguístico e passa a ser investigado como unidade da língua que se converte em unidade de conhecimento e comunicação especializada quando utilizada em domínios específicos. Assim, o termo é, sobretudo, uma unidade léxica que assume a condição de unidade de especialidade em função do domínio que representa; devendo, por isso, ser investigado somente a partir das relações que estabelece dentro do domínio ao qual está inserido. Desta forma, o termo passa a ser concebido como elemento linguístico e a Terminologia é compreendida como uma ciência autônoma, de caráter interdisciplinar, com objeto e metodologia própria.

Nos últimos anos, o computador tem sido um dos principais instrumentos para a realização de pesquisas de natureza terminológica; pois, permite o armazenamento organizado de um grande número de informações e possibilita maior agilidade no manuseio e análise do material pesquisado. A adesão da informática às pesquisas terminológicas gerou, de acordo com Barros (2004, p. 261), “o neônimo 'Terminótica', palavra-valise que fundiu 'Termino(logia)' com '(Informá)tica'”. Maciel (2001) define a Terminótica como o conjunto de operações automatizadas de tratamento dos termos.

A realização de pesquisas que envolvem o conhecimento da linguística com a informática possibilitou o desenvolvimento da Linguística Computacional, "área da ciência linguística voltada para o tratamento computacional da linguagem e das línguas naturais" (Othero e Menuzzi, 2005, p. 25). Ainda de acordo com os autores, a Linguística Computacional pode ser dividida em duas subáreas: a linguística de corpus e o processamento de linguagem natural (PLN). A primeira preocupa-se com investigação em corpora eletrônicos compilados a partir de textos, em vários gêneros, que contenham amostras da linguagem natural. Por sua vez, a segunda visa a linguagem voltada para a construção de softwares e sistemas computacionais específicos; tais como tradutores automáticos, reconhecedores de voz, geradores automáticos de resumos.

Como disciplina científica, a Linguística Computacional "cria instrumentos de composição, extração, análise, manipulação e processamento de dados linguísticos em textos, dando também grande contribuição à elaboração de ferramentas que auxiliam muito o trabalho 
dos terminólogos" (Barros, 2004, p. 262). Quanto à Linguística de Corpus, Berber Sardinha (2004) destaca que ela se ocupa com a coleta e a exploração de corpora, por meio de dados linguísticos coletados criteriosamente, objetivando a análise de uma língua ou de uma variedade linguística. O objeto de estudo dessa disciplina científica é o corpus linguístico em todas as suas acepções.

Barros (2004), destaca a necessidade de distinguir entre proceder a pesquisa linguística em corpus, da pesquisa em Linguística de Corpus. Segundo a terminóloga, a primeira se caracteriza por estudos de caráter linguístico que são efetuados a partir de dados extraídos de um corpus. Por sua vez, a segunda constitui reflexões teóricas sobre a própria disciplina científica Linguística de Corpus, e considera, dentre outros aspectos, o objeto de estudo, metodologia, procedimentos, arcabouço teórico, aplicações de conhecimentos, produtos resultantes de seu trabalho. Nesta pesquisa, dada a metodologia que adotamos para a análise das unidades léxicas mandioca e macaxeira, consideramos a percepção de pesquisa terminológica em Linguística de Corpus. A seguir, apresentamos a metodologia de nossa pesquisa.

\section{Metodologia da pesquisa}

Inicialmente, cumpre destacar que o objeto de estudo deste artigo, as unidades terminológicas compostas pelas lexias mandioca e macaxeira, compõem o corpus de estudo denominado TERMani - Terminologia da Mandioca. Esse corpus é formado a partir de dois subcorpora: subcorpus especializado ( $\mathrm{ScE}$ ), composto por textos cujos autores possuem algum tipo de formação na área das Ciências Biológicas e/ou em áreas afins; e o subcorpus nãoespecializado (ScNE), composto por textos cujos autores não possuem formação na área das Ciências Biológicas, nem em outras áreas afins. Uma descrição mais detalhada das fontes e da maneira como foi constituído esse corpus se encontra em (Cordeiro-Oliveira e Babini, 2016).

A constituição do TERMani a partir de dois subcorpora partiu da nossa observação de que, no estado do Acre, os discursos especializado e não-especializado a respeito da cultura da mandioca se entrecruzam, possibilitando o intercâmbio linguístico entre o público especializado, geralmente engenheiros da Embrapa - Acre, pesquisadores e professores da área das Ciências Biológicas e outras áreas afins, com o público não-especializado: comerciantes, agricultores e grupos familiares que conservam as tradições locais dos que residem nesta parte da floresta amazônica. O referido corpus foi utilizado para a elaboração do "Dicionário 
Terminológico Onomasiológico dos Termos Fundamentais da Mandioca", produto final de nossa investigação sobre a terminologia da mandioca no estado do Acre.

Considerando que o dicionário foi constituído a partir do TERMani, e tendo em vista a representatividade do dicionário no que tange a cultura da mandioca no estado do Acre, procedemos a análise das duas unidades lexicais a partir do CE. Para isso, recorremos ao programa WordSmith Tools (Scott, 2012), versão 6.0 e duas de suas ferramentas; a saber: WordList (Lista de Palavras) e o Concord (Concordância).

Com o uso da primeira, objetivamos gerar a lista de estatística e frequência do nosso CE, observando a representatividade e quantidade de vezes em que as duas lexias eram mencionadas. Nessa etapa, consideramos os dois subcorpora que compõem o CE, assim como os tipos de textos que os constituem; haja visto a nossa hipótese inicial de que o termo mandioca é mais frequente no ScE e termo macaxeira no ScNE.

Por sua vez, a segunda ferramenta, o Concord, nos permitiu conhecer a listagem das ocorrências relativas ao uso dos termos a partir do contexto. Neste momento, conseguimos identificar em quais tipos de textos as unidades lexicais era utilizadas. A ferramenta também possibilitou a observação das variações para o termo macaxeira, nos permitindo a compreensão dos motivos que fazem com que o termo mandioca apresente maior número de ocorrências. Na próxima seção, apresentamos a discussão, análise dos dados e o resultado da pesquisa.

\section{Discussão, análise dos dados e resultados da pesquisa}

Apesar das unidades léxicas mandioca e macaxeira receberem, geralmente, o tratamento de quase-sinônimos, a antropóloga Roberta Rizzi (2011) destaca que a principal classificação taxonômica popular da mandioca é a que opõe as mandiocas mansas (também chamadas de aipim ou macaxeira) e as mandiocas bravas (chamadas de mandioca por oposição a macaxeira e aipim). A dissemelhança entre essas duas espécies está relacionada às diferentes concentrações de ácido cianídrico $(\mathrm{HCN})$ presentes em cada variedade. Assim, as mandiocas mansas (aipins ou macaxeiras, dependendo da região) apresentam baixo teor de ácido cianídrico, enquanto as mandiocas bravas (mandioca) possuem alto teor de ácido cianídrico.

No entanto, quando observamos os nomes que designam os derivados da planta, constatamos que as unidades de especialidade mandioca e macaxeira nomeiam produtos

\footnotetext{
${ }^{4}$ O público-alvo do Dicionário Terminológico Onomasiológico dos Termos Fundamentais da Mandioca são: pesquisadores, professores e alunos dos cursos técnicos, de graduação e pós-graduação, especialmente os que atuam na área das Ciências Biológicas e áreas afins.
} 
específicos, não sendo possível o uso alternativo; por exemplo: no café da manhã, come-se a "macaxeira" cozida com manteiga; em qualquer lanchonete, encontramos o "quibe de macaxeira", e no mercado é possível adquirir a "farinha de mandioca". No estado do Acre, ninguém comercializa o "quibe de mandioca" ou compra a "farinha de macaxeira"; tais construções sintagmáticas foram cristalizadas na cultura, e consequentemente no dialeto acreano.

Quando consideramos os sintagmas terminológicos "farinha de mandioca" e "quibe de macaxeira", observamos que, embora não haja, popularmente, uma distinção entre os termos mandioca e macaxeira, o processo de nomeação dos derivados da planta reporta critérios científicos. As mandiocas (alto teor de $\mathrm{HCN}$ ) são propícias para a produção de farinha, enquanto as macaxeiras (baixo teor de $\mathrm{HCN}$ ) são inadequadas para a produção de farinha e ideais para o consumo na forma in natura.

Acreditamos que, pelo menos, dois fatores contribuem para a construção dessa consciência linguística quanto ao uso desses termos: em primeiro lugar, os investimentos do Governo Estadual em programas de incentivo destinados aos produtores rurais. Durante o processo de execução dos programas, os trabalhadores agrícolas têm contato com técnicos da Embrapa - Acre, engenheiros agrícolas e outros profissionais que, além de fazerem uso dos termos técnicos-científicos, distinguem as espécies mansas e bravas da mandioca. Naturalmente, com o passar do tempo os agricultores incorporam, mesmo que inconscientemente, o vocabulário especializado em seus discursos.

Em segundo lugar, destacamos a política de exportação da farinha para as demais regiões do país e para o exterior. Durante os últimos anos, o Governo do Estado do Acre fomentou iniciativas para a exportação da farinha produzida em Cruzeiro do Sul. Tal ação resultou na produção de embalagens personalizadas para a divulgação e comercialização da "Farinha de Mandioca de Cruzeiro do Sul" apesar de a planta ser popularmente conhecida pelos moradores do município e demais cidades do Vale do Juruá como macaxeira. Nesse contexto, o uso do termo mandioca é proposital ao objetivo; ora, se mandioca é o termo mais conhecido a nível nacional para designar a planta, e se a proposta é o mercado de exportação, justifica-se o uso da unidade léxica.

Em censura ao termo utilizado para a nomeação do produto, o jornalista acreano Altino Machado publicou em seu $\log ^{5}$ uma crítica ao alto investimento feito pelo Governo do Estado

\footnotetext{
5 Disponível em: <http://www.altinomachado.com.br/search?q=farinha+de+macaxeira >. Acesso em 07 de nov. 2015 .
} 
para a confecção das embalagens. A seguir, apresentamos o texto do jornalista, intitulado "Farinha de Macaxeira":

A farinha de macaxeira, apelidada de farinha de mandioca no governo da florestania, tinha mesmo que virar peça de museu.

Não conquistou o mercado importador tampouco pode ser consumida pelos acreanos devido o custo das embalagens. O governo estadual gastou muitos milhares de reais para gerar esse fracasso.

Quem quiser conhecer as embalagens da "farinha de mandioca" deve visitar o Memorial dos Autonomistas. Mas a farinha de macaxeira produzida em Cruzeiro do Sul continua sendo a mais saborosa do mundo.

Farinha de mandioca é papo de colonizador. (BLOG DO ALTINO MACHADO, 2007, http:// www.altinomachado.com.br)

O posicionamento do jornalista constitui uma manifestação às inúmeras críticas que envolviam não só o valor gasto para a produção das embalagens - atualmente mais simples; como também ao uso do termo mandioca para denominar a farinha produzida em um município onde o termo popularmente mais utilizado é macaxeira.

Tendo em vista o tratamento dado às unidades léxicas mandioca e macaxeira no processo de nomeação dos produtos derivados da planta, realizamos análise contrastiva dos termos utilizando o programa WordSmith Tools (Scott, 2012), versão 6.0 e duas de suas ferramentas; a saber: WordList (Lista de Palavras) e o Concord (Concordância). Para a análise, tomamos as informações contidas no TERMani e em seus dois subcorpora, conforme descrição a seguir.

Com o auxílio do WordList geramos as listas de estatística e frequência do TERMani com o propósito de verificarmos o tamanho do CE e a frequência de uso dos termos mandioca e macaxeira. Abaixo, apresentamos, na Figura 1, o resultado, gerado pelo programa, para a lista de estatística.

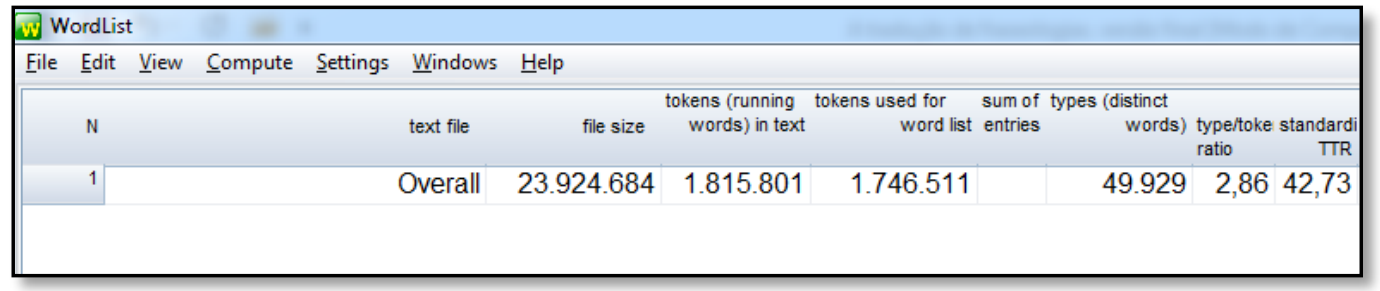

Figura 1 - Dados estatísticos gerais do TERMani, gerados no WordList.

Fonte: Cordeiro-Oliveira (2019).

O programa identificou 1.815.801 tokens, referente ao número total de palavras presente no TERMani; e 49.929 types, concernente a quantidade de palavras diferentes do corpus, contadas apenas uma vez. Após identificamos a quantidade de palavras que constituem o CE, 
e tendo em vista o uso dos termos mandioca e macaxeira no estado do Acre, efetuamos a busca da lista de frequência das duas unidades léxicas, com o propósito de verificarmos qual a mais utilizada, e em quais contextos. O programa apresentou os resultados apresentados na Figura 2.

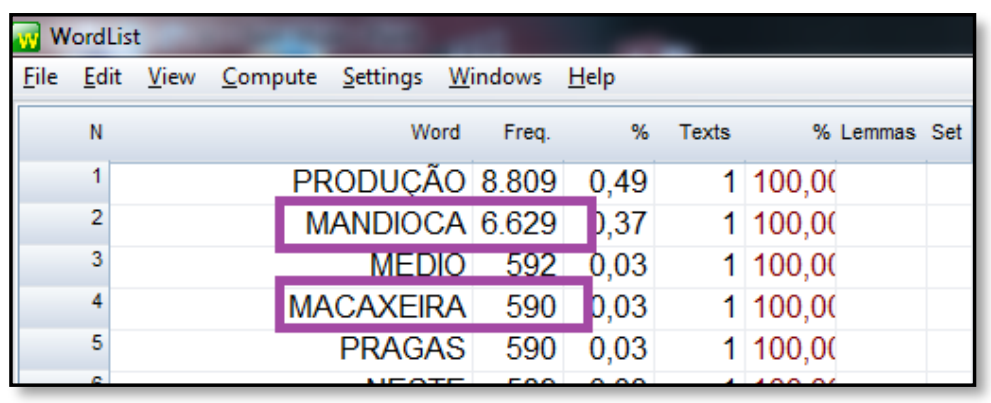

Figura 2 - Lista de frequência gerada no WordList para as lexias mandioca e macaxeira Fonte: Cordeiro-Oliveira (2019).

A partir dos resultados gerados pelo programa, percebemos que a frequência do termo mandioca é superior - 6.629 tokens, quando comparado com o termo macaxeira - 590 tokens. Contribui para esta estatística, o fato de o ScE ser mais extenso em relação ao ScNE. Por se tratar de textos produzidos por especialistas, sobretudo da área das Ciências Biológicas, há maior ocorrência do termo mandioca mesmo quando faz referência às variedades denominadas mansas; conforme citação, extraída do ScE, apresentada abaixo:

Segundo Cury (1993), a migração de material genético varietal de mandioca é uma das responsáveis pelo fluxo gênico entre diferentes roçados de mandioca e regiões geográficas, pois a dispersão natural de sementes e gametas via pólen é muito limitada. (SCHOTT, p. 20, 2009, grifo nosso)

Na citação acima, percebemos que mandioca é empregado no sentido geral da planta, e não apenas para fazer referência às variedades que apresentam alto teor de $\mathrm{HCN}$. O uso do termo é frequente mesmo nos textos em que o autor tem a proposta de discorrer sobre as variedades próprias para o consumo in natura. Para exemplificar essa afirmação, apresentamos a citação abaixo, retirada de um texto que compõe o ScE, cujo título é “Características culinárias de etnovariedades de macaxeira da Terra Indígena Kaxinawa de Nova Olinda, Feijó, Acre”.

O objetivo deste trabalho foi avaliar as características culinárias de etnovariedades de mandioca da Terra Indígena Kaxinawa de Nova Olinda. O experimento de campo foi conduzido no Campo Experimental da Embrapa Acre com dez genótipos entre abril de 2014 a junho de 2015. Os testes culinários foram realizados no Laboratório de Tecnologia de Alimentos da Embrapa Acre onde foram avaliados os parâmetros: porcentagem de água absorvida/perdida, facilidade de descascamento, cor da polpa, textura, plasticidade, pegajosidade e o tempo de cozimento usando cozedor Mattson modificado no qual toletes de mandioca foram posicionados abaixo de 24 
pinos e submersos em água sob fervura. Os resultados das médias obtidas para as variáveis; água absorvida/perdida, textura e porcentagem de toletes cozidos em até 30 minutos foram submetidos à análise de variância ao nível de 5\% de probabilidade. De acordo com os resultados encontrados, as etnovariedades de macaxeira Amarelinha e Juriti apresentaram baixo tempo de cozimento e melhores padrões de massa cozida. Estes genótipos são promissores para futuros trabalhos de melhoramento de mandioca, pois apresentaram as boas características culinárias mesmo em colheita tardia demostrando grande potencial para a exploração como mandioca de mesa. (SIVIERO [et al.], p. 237, 2015, grifo nosso)

Ao analisarmos o uso dos termos mandioca e macaxeira, apresentados anteriormente, podemos perceber que no início da citação os autores substituem macaxeira, indicado no título, por mandioca; posteriormente, o termo mandioca passa a ser utilizado no sentido de sinônimo de macaxeira, e, por fim, ocorre o emprego do termo mandioca de mesa - variação de macaxeira. Ao longo do texto completo, identificamos 25 tokens para mandioca e 16 tokens para macaxeira; embora os autores tenham identificado no título a intenção de discorrer sobre as características das variedades mansas (macaxeiras) presentes na Terra Indígena Kaxinawa de Nova Olinda, município de Feijó, estado do Acre. Acreditamos que a preferência pelo termo mandioca no ScE seja resultado do caráter técnico-científico e do emprego/uso mais frequente no âmbito nacional.

Com o propósito de visualizarmos melhor o usos das duas lexias no TERMani, utilizamos a ferramenta Concord do WordSmith Tools. A ferramenta produz a listagem das ocorrências relativas ao uso dos termos a partir do contexto. A Figura 3 constitui uma mostra do resultado gerado para a unidade terminológica mandioca.

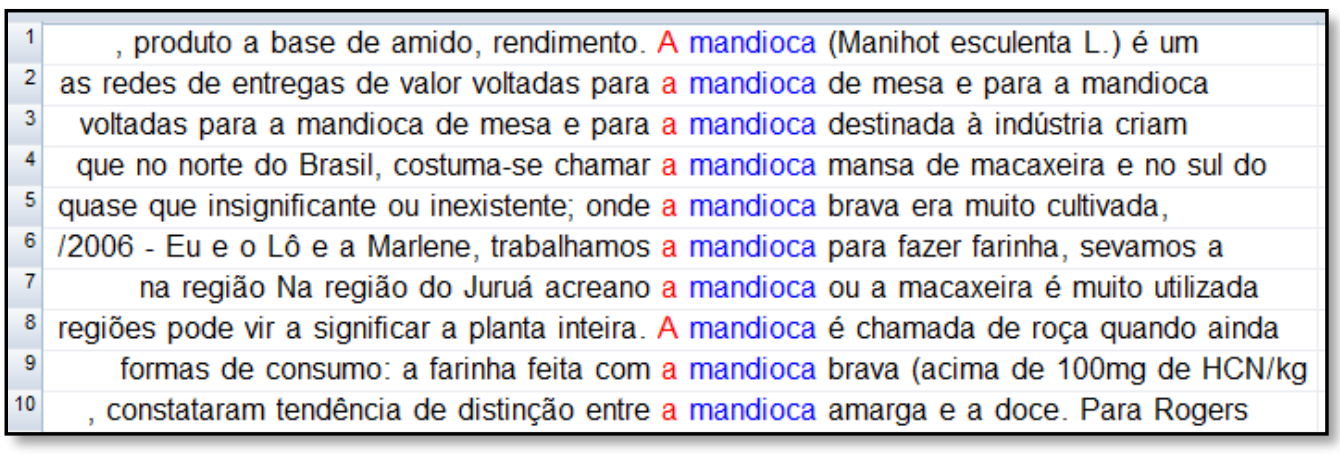

Figura 3 - Linhas de concordância do termo "mandioca", geradas no Concord. Fonte: Cordeiro-Oliveira (2019).

Pelo resultado representado na Figura 3 identificamos, pelo menos, três empregos da unidade terminológica: 
$1^{\circ}$ - no sentido geral, referente à planta, conforme linhas de concordância 1 e 8 " $[\ldots]$ produto a base de amido, rendimento. A <mandioca> (Manihot esculenta L.) é um [...]" e "[...] regiões pode vir a significar a planta inteira. A < mandioca $>$ é chamada de roça quando ainda [...]"; $2^{\circ}$ - como variação do termo macaxeira, exemplificado na linha de concordância de número 7 "Na região do Juruá acreano a <mandioca> ou macaxeira é muito utilizada; $3^{\text {o }}$ - com o valor de antonímia das variedades que apresentam baixo teor de $\mathrm{HCN}$, segundo a linha de concordância 3 “[...] voltadas para a mandioca de mesa e para a $<$ mandioca $>$ destinada à indústria criam $[\ldots] ”$.

O resultado gerado pelo Concord confirmou nossa hipótese inicial: o termo mandioca, por seu aspecto técnico-científico, é privilegiado nos discursos especializados quando comparado ao termo macaxeira. No processo de designação dos cultivares, a unidade léxica é inserida como núcleo do sintagma terminológico, podendo indicar tanto as variedades com baixo teor de HCN (macaxeiras), quanto as que apresentam alto teor de HCN (mandiocas), conforme podemos perceber em "mandioca de mesa", empregado nas linhas de concordâncias 2 e 3; "mandioca brava", presente nas linhas 5 e 9; além de "mandioca amarga" e "mandioca doce", usadas na linha de concordância 10. Logo, esse tipo de construção sintagmática colabora para o baixo uso do termo macaxeira no $\mathrm{ScE}$.

Com o mesmo propósito e utilizando a mesma ferramenta, realizamos busca para a unidade léxica macaxeira, e obtivemos o resultado parcialmente apresentado na Figura 4.

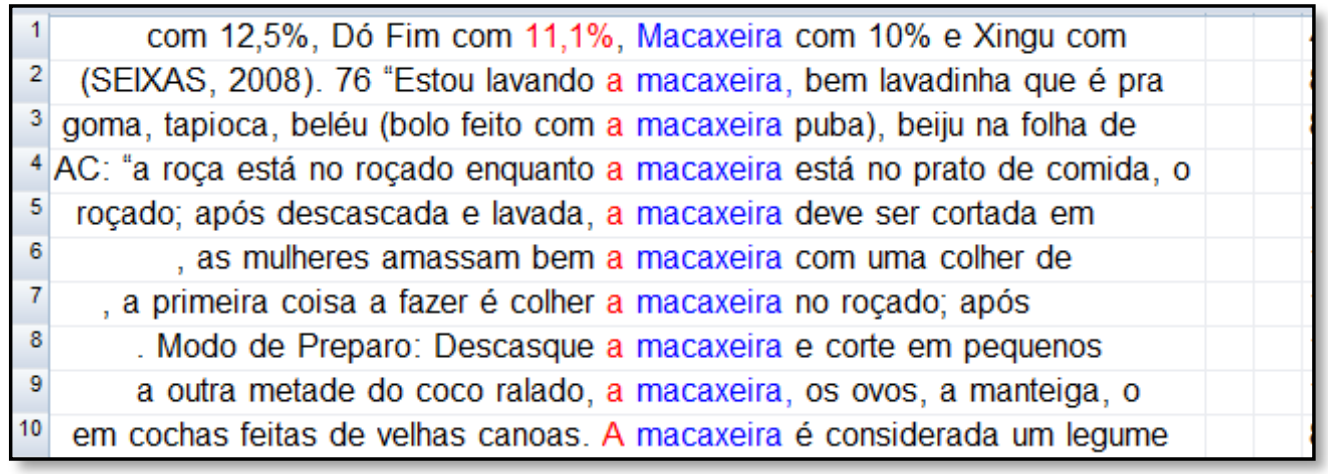

Figura 4 - Linhas de concordância do termo "macaxeira", geradas no Concord. Fonte: Cordeiro-Oliveira, 2019.

A amostra apresentada na Figura 4 nos revela que o termo macaxeira é mais utilizado em piadas, receitas, crônicas; ou seja, nos textos que compõem o ScNE. Apesar disso, mesmo no ScNE, o termo macaxeira não é exclusivo; pois sempre que há referência à farinha, a lexia que completa o sintagma terminológico é mandioca e não macaxeira. Pois, conforme destacado anteriormente, em algumas construções sintagmáticas há a exclusão de um termo em relação 
ao outro termo; por exemplo: quibe de macaxeira - e nunca quibe de mandioca; farinha de mandioca - e nunca farinha de macaxeira. Logo, temos duas lexias que ora competem entre si o mesmo sentido e o mesmo valor de verdade, e ora são elementos de distinção.

\section{Conclusão}

Ao analisarmos o uso das unidades léxicas mandioca e macaxeira no estado do Acre, tomamos o CE denominado TERMani. Esse corpus é formado por dois subcorpora: um subcorpus especializado, que reúne textos cujos autores possuem formação na área das Ciências Biológicas e/ou em áreas afins; e um subcorpus não-especializado, composto por textos cujos autores não possuem formação na área de Ciências Biológicas. O referido corpus foi utilizado para a elaboração do "Dicionário Terminológico Onomasiológico dos Termos Fundamentais da Mandioca. Material composto por 446 termos que reúne a terminologia da mandioca no estado do Acre; destes, 284 são termos privilegiados e 162 são termos remissivos ou variantes.

Ao iniciarmos nossa análise, apresentamos a principal classificação taxonômica popular da planta a fim de destacar a distinção científica entre os dois termos. Destacamos que, enquanto as mandiocas mansas, também chamadas de aipim ou macaxeira, apresentam baixa concentração de ácido cianídrico (HCN); as mandiocas bravas ou simplesmente mandioca, em oposição às macaxeiras, apresentam alto teor de ácido cianídrico.

Uma vez esclarecidos os conceitos, discutimos sobre a composição de alguns sintagmas terminológicos compostos pelas lexias. Identificamos que, no estado do Acre, os termos que designam os derivados da planta apresentam uma estrutura fixa; embora na região as duas unidades léxicas recebam o tratamento semelhante quanto ao significado. Assim, é pouco provável construções como: farinha de macaxeira e quibe de mandioca. Questionamos sobre as causas dessas construções e recorremos ao programa WordSmith Tools (Scott, 2012), versão 6.0 para analisarmos o uso das lexias no TERMani: corpus de estudo da Terminologia da mandioca no estado do Acre.

Com o auxílio do WordList geramos as listas de estatística e frequência do TERMani com o propósito de verificarmos o tamanho do CE e a frequência do uso dos termos mandioca e macaxeira. Quanto ao tamanho do corpus, o programa identificou 1.815.801 tokens e 49.929 types. No que tange às frequências das duas unidades léxicas, percebemos que o termo mandioca apresenta 6.629 tokens e o termo macaxeira 590 tokens. Contribui para este resultado o fato de o ScE ser mais extenso em relação ao ScNE. 
Por sua vez, o Concord produziu uma lista de ocorrências relativas ao uso dos termos a partir do contexto. Essa etapa nos possibilitou a observação do uso dos dois termos a partir do contexto em cada subcorpus. Quando submetemos o ScE para análise no Concord, identificamos o uso de expressões como: mandioca mansa, mandioca doce e mandioca de mesa, em substituição ao termo macaxeira. Acreditamos que o uso do termo mandioca, em detrimento ao termo macaxeira, se deve ao fato de ser o termo mais corrente nacionalmente; e por isso, mais frequente nos textos especializados, tais como: comunicados técnicos, artigos, dissertações e teses. No ScNE também identificamos a presença do termo mandioca, embora esse subcorpus seja composto por textos não-especializados, como: piadas, notícias de jornais e receitas, por exemplo. Nesse subcorpus, o termo mandioca é utilizado com frequência para designar o derivado farinha de mandioca.

Pelos resultados obtidos a partir da análise dos dados, concluímos que embora os dois termos apresentem, popularmente, significados semelhantes, distinguem-se quanto ao derivado que nomeiam. Assim, ainda que no estado do Acre os termos mandioca e macaxeira sejam duas formas utilizadas para designar a planta, em algumas construções sintagmáticas há a exclusão de um termo em relação ao outro: farinha de mandioca e nunca farinha de macaxeira, ou quibe de macaxeira em oposição a quibe de mandioca. Logo, temos duas lexias que ora competem entre si o mesmo sentido e o mesmo valor de verdade, e ora são elementos de distinção.

\section{REFERÊNCIAS}

BARROS, Lídia Almeida. Curso básico de terminologia. São Paulo: Editora da Universidade de São Paulo, 2004.

BERBER SARDINHA, T. Linguística de corpus. Barueri, São Paulo: Manole, 2004.

BERGO, Celso Luís. A agricultura do estado do Acre: a Amazônia brasileira em foco. Comissão Nacional de Defesa e pelo Desenvolvimento da Amazônia, n. 21, p. 60-66, 1993.

CABRÉ, Maria Teresa. La terminología: representación y comunicación. Institut Universitari de Linguística Aplicada Universitat Pompeu Fabra. GI. 635.2010, ISBN: 978.84.92707.58.4. Barcelona: 2005.

CORDEIRO-OLIVEIRA, Simone; BABINI, M.. A Terminologia da Macaxeira: constituição de um corpus. Debate Terminológico, v. 15, p. 32-44, 2016.

CORDEIRO-OLIVEIRA, Simone. Dicionário Terminológico Onomasiológico dos Termos Fundamentais da Mandioca. Tese apresentada à Universidade Estadual Paulista Júlio de Mesquita Filho - Unesp, São Paulo: 2019. 
KRIEGER, Maria da Graça. FINATTO, Maria José Bocorny. Introdução à terminologia: teoria e prática. São Paulo: Contexto, 2004.

MACIEL, A. M. B. "TERMISUL e Terminótica”. In: KRIEGER, Maria da Graça; MACIEL, Anna Maria Becker Maciel. (Orgs.) Temas de terminologia. Porto Alegre/São Paulo: Ed. Universidade/UFRGS/Humanitas/USP, 2001. 344-348.

ORENHA-OTTAIANO, Adriane. Unidades fraseológicas especializadas: colocações e colocações estendidas em contratos sociais e estatutos sociais traduzidos no modo juramentado e não-juramentado. Tese apresentada à Universidade Estadual Paulista Júlio de Mesquita Filho - Unesp, São Paulo: 2009.

OTHERO, G. A.; MENUZZI, S. M.. Lingüística Computacional: teoria \& prática. São Paulo: Parábola Editorial, 2005.

RIZZI, Roberta. Mandioca: processos biológicos e socioculturais associados no Alto Juruá, Acre. Dissertação de Mestrado. Campinas, SP: 2011.

SIVIERO, A. [et al.]. Características culinárias de etnovariedades de macaxeira da terra indígena kaxinawá de Nova Olinda, Feijó, Acre. In: Congresso Brasileiro de Mandioca, 2015, Foz do Iguaçú. Anais do Congresso Brasileiro de Mandioca, X. Marechal Candido Rondon: SBM, 2015. v. 10. p. 237-241.

SCHOTT, B. [et al.]. Caracterização botânica de variedades de mandioca do Acre. In: Congresso Brasileiro de Mandioca, 7, 2009, Botucatu. Anais do Congresso Brasileiro de Mandioca, 7. Associação Brasileira de Mandioca, 2009.

SCOTT, M. 2012 WordSmith tools: version 6.0. Oxford University Press.

VELTHEM, Lucia Hussak Van; KATZ, Esther. A farinha especial: fabricação e percepção de um produto da agricultura familiar no vale do Rio Juruá, Acre. Boletim do Museu Paraense Emílio Goeldi. Ciências Humanas, v. 7, p. 435-456, 2012

WÜSTER, Eugen. Introducción a la teoria general de la terminología y a la lexicografia terminológica. Responsable de la edición: M. Teresa Cabré. Institut Universitari de Linguística Aplicada. Universitat Pompeu Fabra. Barcelona: 1998.

Recebido em 24/05/2020. Aceito em 16/08/2020. 